\title{
EMOTION UNDERSTANDING IN CHILDREN \\ WITH HEARING IMPAIRMENT
}

\author{
Xie Yuhan ${ }^{1}$
}

\begin{abstract}
Emotion understanding refers to the ability to recognize, comprehend and infer emotions, which is crucial to the development of social competence and mental health in children with hearing impairment. Researches on understanding emotions in hearing impaired children are introduced and reviewed in this article based on three aspects: recognizing emotion, understanding the cause of emotion, and understanding display rules of emotion. Plausible interpretations are analyzed, and study issues needed to be explored further in the future researches are put forward.
\end{abstract}

\section{Key words}

Emotion understanding, recognizing emotion, understanding the cause of emotion, understanding display rules of emotion.

\section{Introduction}

Emotion understanding is the ability to take the emotional perspective of another person and infer or estimate others' likely feeling or perception (Harris, 1993; Schwartz \& Trabasso, 1984). Izard and Harris (1995) define emotion understanding to be consciously comprehending emotion processing (e.g. emotion state and emotion adjusting) and how emotion works. Saarni et al. (1998) present that emotion understanding is the ability to "understand what others are feeling" in concise terms. Cutting and Dunn (2002) describe emotion understanding as the capacity to comprehend and infer meaning from the actions, goals, and perspectives of other people that are necessary to facilitate meaningful and appropriate social interactions. In a word, emo-

1 Xie Yuhan, Lecture, Faculty of Education Science, Sichuan Normal University, China; doctoral student, Institute of Special Education, Faculty of Education, Palacký University, Olomouc, Czech Republic. 
tion understanding refers to the ability to recognize, comprehend and infer emotions.

Emotion understanding is an important component of social perception in the theory of mind (Tager-Flusber \& Sullivan, 2000); it is also considered as a central component of children's social-emotional competence and adjustment (Halberstadt, Denham, \& Dunsmore, 2001; Cole et al., 2009). Understanding emotion involves attending to and interpreting the emotional valence of an emotional expression in facial expression, vocal expression, and "situational elicitors of emotion" (Saarni, Mumme, \& Campos, 1998). It may have far-reaching consequences for their personal and academic success (Greenberg \& Kusche, 1993), also play adaptive role in both intra-psychic regulation and interpersonal interaction, is the major factor in everyday communication (Barrett, 1993). Socially inadequate expression one's own or understanding of other person's emotions can create easily a climate of interpersonal misunderstandings (Rieffe \& Terwogt, 2000), and lead to ineffective interactions.

Many researches find that children with hearing impairment have many difficulties in peer relationships and interactions (Nunes et al., 2001; Weisel et al., 2005; Most, 2007). Some researchers claim that children with hearing impairment are detected to have large amount of distrust, stubbornness, and behavioral problems (Vostanis et al., 1997).They are delayed in psychological and social adjustment (Vernon \& Greenberg, 1999), and in acquiring the theory of mind (Peterson \& Siegal, 2000). These problems might have been closely linked to the difficulties in understanding and expression of emotions in children with hearing impairment.

\section{Emotion understanding of children with hearing impairment}

In case of hearing impaired children, conclusions of researchers' studies on their understanding emotion are not consistent. Many studies demonstrate that hearing impaired children's capacities to predict basic emotions develop at a much later age than hearing children (Harris et al., 1987). Odom, et al. (1973) found that deaf children have trouble in indentifying and interpreting emotional situations. Dyck et al. (2004) discovered that hearing impaired children's inferior performance on emotion recognition and understanding 
tasks reflects delayed acquisition of a broad range of language-mediated abilities. However, Hosie et al. (1998) claimed that despite possible differences in the early socialization of emotion, deaf and hearing children share a common understanding of the emotions conveyed by distinctive facial expressions. Rieffe and Terwogt (2000) found that both deaf and hearing children are capable of correctly predicting typical emotions. Although deaf children did not always come up with accurate emotion predictions immediately, this decreased with age.

Understanding emotion is crucial to the development of social competence and mental health in children with hearing impairment, which should be paid high attention in order to promote development of them. Researches on understanding emotion of children with hearing impairment are introduced and reviewed in this article based on three aspects: recognizing emotion, understanding the cause of emotion, and understanding display rules

of emotion. Plausible interpretations are analyzed, and study issues needed to be explored further in the future researches are put forward.

\subsection{Recognizing emotion}

Recognizing emotion is the basic emotional competence, referring to the capacity of labeling and comprehending emotions in facial expression, indentifying and inferring characters' emotions in various situations. Facial expressions are outward manifestation of the internal emotions, and one can recognize the emotion from others' facial expression. Understanding of emotions in situations refers to recognizing and inferring the emotions of protagonist from certain emotion-arousing situations, which is more difficult than recognizing emotions in facial expression. The perception of emotions in facial expressions and situations is a fundamental aspect of emotion processing, reflecting the basic interpretation of social cues upon which consequent social interactions and behaviors (Pollak et al., 2000).

Odom et al. (1973) asked deaf and hearing children to sort faces portraying nine emotions. Results showed that the deaf children perform as well as hearing children. However, when asking children to match these faces representing emotions with drawing of appropriate emotion-arousing situations, deaf children cannot match faces to the situations as well as hearing children. It indicated that there was no difficulty in recognizing emotions in facial expressions for deaf children; nevertheless, there were much trouble 
in identifying and inferring emotions in situations for them. It appeared that deaf children could not analyze and interpret emotion-arousing events adequately. These outcomes are confirmed by several other researches. Bachara et al. (1980) found that deaf children performed less well than hearing participants on tests of emotional understanding, while requiring them to link emotive situations to facial expressions. Song Wenxia et al. (2010) tested the hearing impaired children's external emotion understanding by means of self-established examination. They obtained similar results, showing that the development of hearing children's understanding external emotion including ability of recognizing facial expression is delayed, relative to hearing children. The study by Gray et al. (2007) examined deaf children on the ability to assign the emotions of anger, sadness, fear, surprise and disgust to the characters in simple stories. Results suggested that deaf children have more difficulties to assign emotions to protagonists in the story than hearing children. Nevertheless, the marked improvement in performance by the older deaf children indicates that they had made considerable gains in their emotional understanding with age. In other words, there is a developmental lag in deaf children understands of emotion in the younger deaf children; however, the ability of understanding emotions of deaf children could be improved markedly with age, older deaf children should perform at a similarly high level to hearing children.

However, Hosie et al. (1998) claimed that when tasks do not request linguistic information, children with hearing impairment do well as hearing children. Deaf children and hearing children at same age were tested for their ability to match photographs of facial expressions of emotion, and to produce and comprehend emotion labels for the expressions of happiness, sadness, anger, fear, disgust, and surprise. The results suggest that there are no significant differences between the abilities of deaf and hearing children in recognizing emotions. Deaf children were even more accurate at labeling disgust expression, and also at labeling fear, than hearing children.

For different types of emotions, the abilities of children to indentifying of them are different. Many studies confirmed that hearing children can identify situations that rise to happiness and sadness more easily than those engendering fear or anger (Denham and Couchoud, 1990; Markham and Adams, 1992). Hosie et al. (1998) examined deaf children on the matching, labeling, and comprehension of facial expressions of emotion showed a similar pattern: 
for both of deaf children and hearing children, happiness and sadness were the most accurately matched expressions and the most accurately produced and comprehended labels. Anger was the least accurately matched expression and the most poorly comprehended emotion label. Disgust was the least accurately labeled expression. The study of Zheng Pei and Ma Weina (2009) got a similar conclusion: the level of recognizing happiness is significant higher than that of anger and fear for hearing impaired children. Gray et al. (2007) also found that for both of deaf children and hearing children, attribution of emotions to story characters with happiness and sorrow is easier than they did with those depicting other emotions (e.g. disgust, fear, surprise, and anger). Assigning emotions to the story with anger is most difficult.

On the other hand, Odom et al. (1973) found that their deaf children scored best on anger and fear, very much at variance with the pattern in hearing children. It is possibly related to the methodological issues in the experiment, in which participants were 15 deaf children in a residential school, who were compared to normal hearing children in kindergarten and second graders. The small size of the sample of deaf children and the questionable generaliziability of deaf children who are educated in a residential setting are particular concerns (Gray et al., 2007).

Sound playing an important role in the emotional development, which usually taking place in an auditory-linguistic context (Fehr and Exline, 1987). The conversations and communication with others is vital to understand one's own and others' emotions, but the impairment of hearing hamper interactions between children and parents, peers and others (Lederberg and Mobley, 1990); Parents and caregivers are also less likely to give deaf children explanations of their emotions (Vaccari \& Marschark, 1997). Hearing impaired children lack opportunities to engage in various interactions with family members, caregivers, and other children that are likely to give rise to spontaneous conversations about emotion. These factors hinder the development of social interaction, abstract thinking, and understanding emotions in hearing impaired children, leading to difficulties in indentifying emotions in facial expressions and situations for them (Odom et al., 1973; Song Wenxia et al., 2010). With increasing of social experience, the capacity to understand emotion would be improved with age, so older deaf children should perform better than younger deaf children in tasks of understanding emotion (Gray et al., 2007). However, Hosie et al. (1998) declared that happiness, sadness, 
anger, fear, disgust, and surprise represent emotions for which there exist clear and unambiguous facial expressions, and these facial expressions are displayed within the first year of life by both hearing (Izard et al., 1995) and deaf infants (Snitzer et al., 1990). Moreover, the normal development of the ability to read facial expressions of emotion is only minimally dependent on environmental input and is, therefore, relatively independent of experience. In case of deaf children, their experience which is different from hearing children provides alternative inputs on which deaf children are able to capitalize. So, deaf and hearing children share a common conceptual understanding of the facial expressions, and have similar pattern to comprehension of emotions.

\subsection{Understanding the cause of emotion}

Children not just recognize others' emotions, but also can infer the cause of emotions, understanding that others' emotions depend on their subjective desires and beliefs. Children are able to accurately predict that protagonist will be happy if he/she receives what he/she desired, and protagonist will be unhappy if he/she is frustrated in fulfilling his/her desire, when children are at age of about 3 (see review of Li Jia \& Su Yanjie, 2004).Researchers claim conformably that children's understanding of emotions based desires develop earlier than their understanding of emotions based on beliefs (Harris \& Johnson, 1989; Baron-Cohen \& Harris, 1998). The results of an experiment showed that children at 3 are not able to understand emotions based on beliefs accurately, few children at 4 and most children at 6 can understand emotions base on beliefs. In other words, children at 4 began to understand the emotions related to beliefs and such capacity developed well when they are aged 6 (Harris \& Johnson, 1989). The study of Baron-Cohen (1998) also confirmed this conclusion, indicating that $89.5 \%$ of children aged between 4 to 6 can understand emotions based on desires, and only $73.7 \%$ of children can understand emotions based on beliefs. Additionally, children also appreciate that different people can have different desires and beliefs and others' desires and beliefs can differ from their own (Tang Hong, 1996).

About understanding of emotions based on desires and beliefs, there are little studies for hearing impaired children. Researches focusing on their understanding of the relationship between beliefs and emotions find that the hearing impaired children's ability of understanding emotions based on beliefs delays, compared with hearing children. Steeds et al. (1997) imple- 
mented the Smartie experiment, providing deaf children aged 5-12 years (mean 9 years old)with situation in which the protagonist falsely believed that a Smartie box contained Smaties, whereas in actual, the Smartie box contained pencils. Participants were asked to predict how the protagonists felt when he was given the box with not discovering the box's actual content. The result demonstrated that $70 \%$ of participants predicted that the protagonist would be happy when he received the Smartie box. The performance of hearing impaired children at age of 9 years old is compatible to that of hearing children at age of 6 years old, then it can be inferred that hearing impaired children's ability understanding emotions based on beliefs lag behind that of hearing children.

Some researchers state that hearing impaired children understand emotions referring more frequently to desires than hearing children. The research of Rieffe \& Terwogt (2000) focused on deaf children's understanding emotions governed by subjective mental states (beliefs and desires), asking deaf and children to explain emotions (happiness, anger, or sadness) felt by characters in various situations. The results showed that while the deaf children made as many as references to mental states as did the hearing children, they tend to neglect causal factors and mention more desires to explain character's emotions than beliefs; their reference to desires largely exceeded those of hearing children, and these desires references among deaf children even increased with age. The study of Reffe et al. (2003) also demonstrated that deaf children tend to concentrate primarily on the fulfillment of desires in their emotion predictions and explanations, whereas they neglect the factors that had led to the negative outcome.

The hearing impaired children's deficits in understanding emotions based on beliefs many be related to their deficits in the theory of mind. Some researches on the theory of mind using standard false beliefs tasks obtain the results: $65 \%$ to $90 \%$ of deaf children at mean age of 10 years old failed in simple false tasks, which were accurately accomplished by hearing children at 5 years old (Peterson \& Siegel, 1998; Russell et al., 1998). Rieffe and Terwogt (2000) argued that understanding the subjectivity of desires can be learned nonverbally for deaf children, and they grow up in a mainly hearing society, their time and their communication with others is frequently restricted. Therefore, an economic use of this time seems wise and their frequent references to desires are defensible. 


\subsection{Understanding display rules of emotion}

There is a distinction between real and apparent emotions. People's emotion expressed might not be in accordance with the emotion experienced actually, which is related to the "display rules of emotions". "Display rules of emotions" are recognized as the principles governing whether an emotion should be expressed or concealed (Ekman et al., 1972). During the elementary school years, children develop the awareness of the possible dissociation between, on the one hand, a person's expression (particularly facial expression) of emotion and, on the other, how that person actually feels, such development is important to children's understanding of emotion (Saarni, 1993). Hearing children can use display rules of emotions at early age (3 or 4 years old), inhibiting the expression of emotion in certain social situations: for example, they conceal their disappointment on receiving an undesirable gift (Cole, 1986). Understanding the display rules of emotions is a crucial task for children's socialization, playing a central role in their development of emotion and social competence, facilitating social interactions and selfregulation (Garner \& Power, 1996)

The researches on hearing impaired children's understanding the replay rules of emotions are scanty. One research was done by Hosie et al. (2000), which examined deaf children's understanding of display rules by utilizing short stories scenarios in which a protagonist encounters a situation that is likely to demand some form of emotional regulation. The results showed that deaf children's understanding of display rules is broadly on a par with that of hearing children of the same age, particularly when those rules involve self-protection. However, the development of understanding of the strategic function of prosocial display rules in deaf children may be subject to a degree of developmental lag, relative to hearing children. Hosie et al. interpreted that emotion concealment for prosocial reasons, which is to protect others' feeling, requires a relatively sophisticated awareness and understanding of the mental states of other people. Hearing impaired children prefer to communicate with others using sign language not oral language (Hanakova et al., 2011), however most of them communicate in a spoken language context where their interactions are restrictive, that is not benefit for development of understanding others' mental states (Peterson \& Siegal, 1995; Russell et al., 1998). Therefore, deaf children's ability to regulate their emotional expression to protect other persons' feelings would be delayed. Evidences suggested 
that understanding of emotional display rules in hearing children is at first associated with protection of their own feelings not others' feelings (Zeman \& Garber, 1996), and the ability of understanding prosocial rules develops later. It could be inferred that deaf children's understanding emotional rules for prosocial reasons emerge much later; their performances are seen as displaying a pattern which is typical of younger hearing children (Hosie et al., 2000).

Understanding the replay rules of emotions also reflects in the regulation of emotions, especially controlling negative emotions. Therefore, great many studies on children's understanding of display rules have concentrated upon their regulation of negative affective states (Underwood, Coie \& Herbsman, 1992; Zeman \& Garber, 1996; Zeman \& Shipman, 1996); In particular, expressions of anger are discouraged from an early age (Dunn, Bretherton \& Munn, 1987); Children learn to mask the expression of their emotions to situational circumstances in according to cultural display rules (Malatesta $\&$ Haviland, 1982). For hearing impaired children, studies indicate that deaf children have mask their anger and happiness less frequently than hearing children; Their reasons for masking their true feelings were comparatively selfprotective, whereas hearing children provided more reasons that were prosocial or concerned with norm-maintenance (Hosie et al., 2000). Deaf children show more anger than hearing children, and do so in a less constructive way in keep positive peer relationships (Rieffe \& Terwogt, 2006).The research of Rieffe and Terwogt (2006) examined how deaf and hearing children would communicate their anger towards peers in conflict situations, using a vignette paradigm. The results suggested that deaf children tend to communicate their anger rather bluntly. Whereas the vast majority of the hearing children made an attempt to explain their displeasure, almost half of the deaf children failed to do so. Moreover, deaf children were more pessimistic about receiving an empathic response than hearing children. Deaf children express anger more bluntly, but their overtly aggressive reactions do not exceed those of their hearing peers, not supporting former studies, manifesting that deaf children show more blunt aggression (Murdock \& Lybarger, 1998; VanEldik, 1994). Nonetheless, their reactions to an angering event seemed less beneficial to dealing with the social relationships effectively.

Rieffe \& Terwogt (2006) pointed out that deaf children are emotionally less competent than hearing children, such as blunt expression of anger and impaired insight into the outcome of such behaviors, that is associated with 
deaf children lacking conversations and communications with others, which give opportunities to learn and practice emotional replay rules. Moreover, "emotional coaching" that parents help children to accept and label their emotions, to recognize and acknowledge emotions in others, and also help their children to develop coping strategies and interpersonal problem solving skills (Gottman \& Declaire, 1997), is impoverished to deaf children. Most parents of deaf children talk less about mental states, emotions and their causes, with their deaf children (Vaccari \& Marschark, 1997). These factors prevent the deaf children's development of emotional competence and influence their understanding emotional display rules.

\section{Conclusions}

Several evidences predominantly confirm that the ability of understanding emotion in hearing impaired children is delayed, compared with hearing children, although some researches find their performance in recognizing emotions in facial expression as similar as hearing children((Hosie, et al., 1998). They have trouble in indentifying and interpreting emotional situations (Odom et al., 1973), in understanding external emotion (Song Wenxia et al., 2010), in assigning the emotions to the protagonist in simple stories (Gray et al., 2007). They tend to explain emotions based on desires, not beliefs (Rieffe $\&$ Terwogt, 2000; Rieffe et al., 2003), and are delayed in understanding beliefs (Steeds et al., 1997), neglect the factors leading to negative outcome (Rieffe et al., 2003). Furthermore, there is developmental lag in understanding emotional display rules for prosocial reasons of hearing impaired children, relative to hearing children (Hosie et al., 2000). They are not able to regulate negative emotions adequately, expressing anger much bluntly without explaining their displeasure (Rieffe \& Terwogt, 2006).

The development of emotion understanding relates closely to social interactions, which provide opportunity to learn and develop ability of understanding and expressing emotions. In hearing impaired children, their hearing impairment hampers spoken language's development, making them unable to communicating with family members, peers and others as smoothly as hearing children. Moreover, sign language which is their preferred communication tool with legislative support and high degree of efficiency for its users 
is not presented in sufficient extent (Hanakova et al., 2011). Therefore, they lack abundant opportunities and social experience to learn knowledge about emotions and practice it (Odom et al., 1973; Rieffe \& Terwogt, 2006), so that they may not understand, infer others' emotions in some circumstances, or regulate and express their own emotions appropriately. Moreover, Gottman \& Declaire (1997) claimed that "emotional coaching" is important to develop the capacities of understanding emotion, emphasizing that parents should help their children gain ability of understanding their own and others' emotions. Nevertheless, in fact, "emotional coaching" to children with hearing impairment is insufficient very much. Their parents seldom talk about emotions with them (Vaccari \& Marschark, 1997). In additional, hearing impaired children have difficulties in the theory of mind which is closely associated with emotional competence. Deaf children have difficulties in acknowledging that different people can hold different mental states regarding the same situation (Peterson \& Siegel, 1995, 1998; Russell et al., 1998).Their deficits in the theory of mind may account for their delay in understanding emotion in some degree.

The researches on emotion understanding in children with hearing impairment are not affluent, mainly focusing on recognizing emotions in facial expression and situations, inferring the cause of emotions based on desires and beliefs, and understanding emotion replay rules. But seldom studies explore deeply the influencing factors on understanding emotions of hearing impaired children and the underlying working mechanism also is needed to be probed deeply. Additionally, studies on how to improve hearing impaired children ability to understand and regulate emotions are deficient too. Hence, in future researches, the issues on influencing factors and working mechanism on emotion understanding, and improving programs for hearing impaired children should be discussed enough and explored in depth.

\section{References}

BACHARA, G., RAPHAEL, J., \& PHELAN, W. (1980). Empathy Development in Deaf Preadolescents. American Annals of the Deaf, 125, 38-41.

BARON - COHEN, S. (1998) Does the Study of Autism Justify Minimalist Innate Modularity? Learning and Individual Differences, 10 (3), 179-191.

BARRETT, K. C. (1993). The Development of Nonverbal Communication of Emotion - a Functionalist Perspective. Journal of Nonverbal Behavior, $17,145-169$. 
COLE, P. M. (1986). Children's Spontaneous Control Official Expression. Child Development, 57, 1309-1321.

COLE, P. M., DENNIS, T. A., SMITH-SIMON, K. E., \& COHEN, L. H. (2009). Preschoolers' Emotion Regulation Strategy Understanding: Regulations with Emotion Socialization and Child Self-regulation. Social Development, 2 (18), 324-352.

CUTTING, A. L., \& DUNN, J. (1999). Theory of Mind, Emotion Understanding, Language, and Family Background: Individual Differences and Interrelations. Child Development, 70, 853-865.

DENHAM, S. A. (1986). Social Cognition, Prosocial Behavior, and Emotion in Preschoolers: Contextual Validation. Child Development, 57, 194-201.

DENHAM, S. A., \& COUCHOUD, E. A. (1990). Young Preschoolers' Understanding of Emotion. Child Study Journal, 20, 171-192.

DUNN, J., BRETHERTON, I., \& MUNN, P. (1987). Conversations about Feeling States Between Mothers and Their Young Children. Developmental Psychology, 23, 132-139.

DYCK, M. J., FARRUGIA, C., SCHOCHET, M. I., \& HOLMES-BROWN, M. (2004). Emotion Recognition/Understanding Ability in Hearing or Vision-impaired Children Do sounds, sights, or words make the difference? Journal of Child Psychology and Psychiatry, 45 (4), 789-800.

EKMAN, P., FRIESEN, W., \& ELLSWORTH, P. (1972). Emotion in the Human Face. New York: Pergamon Press.

FEHR, B. J., \& EXLINE, R. V. (1987). Social Visual Interaction: A Conceptual and Literature Review. In Siegman, A. W., \& Feldstein, S. (eds.), Nonverbal Behavior and Communication, Lawrence Erlbaum Associates, Hillsdale, New Jersey, 225-326.

GARNER, P. W., \& POWER, T. G. (1996). Preschoolers' Emotional Control in the Disappointment Paradigm and Its Relation to Temperament, Emotional Knowledge, and Family Expressiveness. Child Development, 67, 1406-1419.

GRAY, C., HOSIE, J., RUSSLE, P., SCOTT, C., \& HUNTER, N. (2007). Attribution of Emotions to Story Characters by Severely and Profoundly Deaf Children. Journal of Developmental and Physical Disabilities, 2 (19), 145-159.

GOTTMAN, J . M., \& DECLAIRE, J. (1997). The Heart of Parenting: Raising an Emotionally Intelligent Child. Utrecht, The Netherlands: Kosmos. 
GREENBERG, M. T., \& KUSCHE, C. A. (1993). Promoting Social and Emotional Development in Deaf Children: The PATHS project. Seattle: University of Washington Press.

HALBERSTADT, A. G., DENHAM, S. A., \& DUNSMORE, J. C. (2001). Affective Social Competence. Social Development, 10, 79-119.

HANAKOVA, A., POTMESIL, M., POTMESILOVA, P., VITOVA, J. (2011). Sign Language and its Awareness. Multi-culture and Schooling Reform International Conference Proceedings (pp. 7-20). Chengdu, China: SCNU.

HARRIS, P. L., OLTHOF, T., TERWOGT, M. M., \& HARDMAN, C. E. (1987). Children's Knowledge of the Situations That Provoke Emotion. International Journal of Behavioral Development, 10, 319-343.

HARRIS, P. L. (1993). Understanding Emotion. In M. Lewis \& J. M. Haviland (Eds.), Handbook of Emotions (pp. 237-246). New York: Guilford Press.

HARRIS, P. L., JOHNSON, C. N, HUTTON, D., ANDDREWS. G. \& COOKE, T. (1989). Young Children's Theory of Mind and Emotion. Cognition and Emotion, 3, 379-400.

HOSIE, J. A., GRAY, C. D., RUSSELL, P. A., SCOTT, C., \& HUNTER, N. (1998). The Matching of Facial Expressions by Deaf and Hearing Children and Their Production and Comprehension of Emotion Labels. Motivation and Emotion, 22, 293-313.

IZARD, C. E., FANTAUZZO, C. A., CASTLE, J. M., HAYNES, O. M., RAYIAS, M. R, \& PUTNAM, P. H. (1995). The Ontogeny and Significance of Infants' Facial Expressions in the First 9 Months of Life. Developmental Psychology, 37, 997-1013.

IZARD, C. E., \& HARRIS, P. (1995). Emotional Development and Developmental Psychopathology. In D. Cicchetti \& D. J. Cohen (Eds.), Developmental Psychopathology: Theory and Methods (pp. 467-503). New York: John Wiley \& Sons.

LEDERBERG, A. R., \& MOBLEY, C. E.(1990). The Effect of Hearing Impairment on the Quality of Attachment and Mother-toddler Interaction. Child Development, 61, 1596-1604.

LI JIA, SU YANJIE. (2004). Children's Emotion Understanding in Their Theory of Mind. Advances in Psychological Science, 12 (1), 37-44.

MALATESTA, C.Z., \& HAVILAND, J. M.(1982). Learning display rules: The Socialization of Emotion Expression in Infancy. Child Development, 53, 991-1003. 
MARKHAN, R., \& ADAMS, K. (1992). The Effect of Type of Task on Children's Identification of Facial Expressions. Journal of Nonverbal Behavior, $16,21-39$.

MOST, T. (2007). Speech Intelligibility, Loneliness, and Sense of Coherence Among Deaf and Hard-of-hearing Children in Individual Inclusion and Group Inclusion. Journal of Deaf Studies and Deaf Education, 12(4), 495-503.

MURDOCK, T. B., \& LYBARGER, R. L. (1998). An Attribution Analysis of Aggression Among Children Who Are Deaf. Journal of the American Deafness and Rehabilitation Association, 31, 10-22.

NUNES, T., PRETZLIK, U., \& OLSON, J. (2001). Deaf Children's Social Relationships in Mainstream Schools. Deafness and Education International, 3(3), 123-136.

ODOM, P. B., BLANTON, R. L., \& LAUKHUF, C. (1973). Facial Expressions and Interpretation of Emotion-arousing Situations in Deaf and Hearing Children. Journal of Abnormal Child Psychology, 1, 139-151.

PETERSON, C. C., \& SIEGAL, M. (1995). Deafness, Conversation and Theory of Mind. Journal of Child Psychology and Psychiatry, 36, 459-474.

PETERSON, C. C., \& SIEGAL, M. (2000). Insights into Theory of Mind from Deafness and Autism. Mind and Language, 15, 123-145.

POLLAK, S. D., CICCHETTI, D., KLORMAN, R., \& BRUMAGHIM, J. T. (1997). Cognitive Brain Event-related Potentials and Emotion Processing in Maltreated Children. Child Development, 68, 773-787.

POLLAK, S. D., CICCHETTI, D., HORNUNG, K., \& REED, A. (2000). Recognizing Emotion in Faces: Developmental Effects of Child Abuse and Neglect. Developmental Psychology, 36, 679-688.

PRTERSON, C. C., \& SIEGAL, M. (1998). Changing Focus on the Representational Mind: Deaf, Autistic and Normal Children's Concept of False Photos, False Drawing and False Beliefs. British Journal of Developmental Psychology, 16, 301-320.

RIBORDY, S. C. (1988). Vignettes for Emotion Recognition Research and Affective Therapy with Children. Journal of Clinical Child Psychology, 17, 322-325.

RIEFFE, C. \& TERWOGT, M. M. (2000). Deaf Children's Understanding of Emotions: Desires Take Preference. Journal of Child Psychology and Psychiatry, 41, 601-608. 
RIEFFE, C., TERWOGT, M. M., \& SMIT, C. (2003). Deaf Children on the Causes of Emotions. Educational Psychology, 23, 159-168.

RIEFFE, C., \&TERWOGT, M. M. (2006). Anger Communication in Deaf Children. Cognition and Emotion, 20 (8), 1261-1273.

RUSSELL, P. A., HOSIE, J. A., GRAY, C. D., SCOTT, C., HUNTER, N., BANKS, J. S., \& MACAULAY, M. C. (1998). The Development of Theory of Mind in Deaf Children. Journal of Child Psychology and Psychiatry, 39, 903-910.

SAARNI, C. (1993). Socialization. In M. Lewis \& J. M. Haviland (Eds.), Handbook of emotions (pp. 435-446). New York: Guilford Press.

SAARNI, C., MUMME, D. L., \& CAMPOS, J. J. (1998). Emotional Development: Action, Communication, and Understanding. In W. Damon \& N. Eisenberg (Eds.), Handbook of Child Psychology: 5th Edition Social, Emotional, and Personality Development (Vol. 3). New York: Wiley \& Sons.

SCHWARTZ, R. M., \& TRABASSO, T. (1984). Children's Understanding of Emotions. In C. E. Izard, J. Kagan \& R. Zajonc (Eds.), Emotions, Cognition, and Behavior (pp. 409-437). Cambridge, MA: Cambridge University Press.

SNITZER Reilly, J., Mclntire, M. L., \& Bellugi, U. (1990). Faces: The Relationship between Language and Affect. In J. Snitzer Reilly, M. L. Mclntire, \& U. Bellugi (Eds.), From Gesture to Language in Hearing and Deaf children (pp. 128-141). Hillsdale, NJ: Erlbaum.

SONG WEN-XIA, LI NA, \& ZHANG FU-JUAN. (2010). A Comparative Study on External Emotion Understanding with Hearing Disorder Children. Chinese Journal of Applied Psychology, 16(1), 80-88.

STEEDS, L., ROWE, K., \& DOWKER, A. (1997). Deaf Children's Understanding of Beliefs and Desires. Journal of Deaf Studies and Deaf Education, 2, 185-195.

TAGER-FLUSBERG, H. \& SULLIVAN, K. (2000). A Componential View of Theory of Mind: Evidence from Williams Syndrome. Cognition, 76 (1), 59-90.

WEISEL, A., MOST, T., EFRON, C. (2005). Initiations of Social Interactions by Young Hearing Impaired Preschoolers. Journal of Deaf Studies and Deaf Education, 10 (2), 161-170.

TANG HONG, FANG FUXI (1996).The Preliminary Study on Moral Judgment of Victimizing Behavior and Relevant Emotional Attribution in Young Children. Acta Psychologica Sinica, 4, 359-366. 
UNDERWOOD, M. K., COIE, J. D., \& HERBSMAN, C. R. (1992). Display Rules for Anger and Aggression in School-age Children. Child Development, 63, 366-380.

VACCARI, C., \& MARSCHARK, M. (1997). Communication between Parents and Deaf Children: Implications for Social-emotional Development. Journal of Child Psychology and Psychiatry, 38, 793-801.

VERNON, M., \& GREENBERG, S. (1999). Violence in Deaf and Hardof-hearing People: A Review of the Literature. Aggression and Violent Behavior, 4, 259-272.

VOSTANIS, P., HAYES, M., DU-FEU, M., \& WARREN, J. (1997). Detection of Behavioral and Emotional Problems in Deaf Children and Adolescents: Comparison of Two Rating Scales. Child Care, Health and Development, 23, 233-246.

ZEMAN, J., \& GARBER, J. (1996). Display Rules for Anger, Sadness and Pain: It Depends on Who Is Watching. Child Development, 67, 957-973. ZEMAN, J., \& SHIPMAN, K. (1996). Children's Expression of Negative Affect: Reasons and Methods. Developmental Psychology, 32, 842-849.

ZHENG PEI, MA WEI-NA. (2009). Development of Deaf Children's Emotion Understanding. Chinese Journal of Clinical Psychology, 5 (17), 584-587.

\section{Contact}

Xie Yuhan

Lecture, Faculty of Education Science, Sichuan Normal University, Chengdu, China Doctoral student, Institute of Special Education, Faculty of Education

Palacký University

Olomouc

Czech Republic

e-mail: yuhanxie2007@163.com 